УДК 551.577.13:546.21(470.311)

\title{
ИЗОТОПНЫЙ СОСТАВ АТМОСФЕРНЫХ ОСАДКОВ В ПРЕДГОРЬЯХ АЛТАЯ: ДАННЫЕ НАБЛЮДЕНИЙ И ИНТЕРПОЛЯЦИИ
}

\author{
Малыгина Наталья Сергеевна',2, \\ natmgn@gmail.com \\ Эйрих Алла Николаевна', \\ allnik608@gmail.com \\ Курепина Надежда Юрьевна', \\ nyukurepina@mail.ru \\ Папина Татьяна Савельевна', \\ tanya.papina@mail.ru \\ 1 Институт водных и экологических проблем СО РАН, \\ Россия, 656038, г. Барнаул, ул. Молодежная, 1. \\ ${ }^{2}$ Алтайский государственный университет, \\ Россия, 656049, г. Барнаул, пр. Ленина, 61.
}

\begin{abstract}
Актуальность. В последние годы соотношения стабильных изотопов кислорода и водорода в атмосферных осадках, полученных на станциях сети Global Network of Isotopes in Precipitation (GNIP), активно используются в качестве надежных маркеров современных, а также прогнозируемых климатических и гидрологических изменений. Однако для обширной территории России наборы таких данных существенно ограничены не только в пространстве, но и по времени. Одним из наиболее перспективных районов исследования в данном направлении является предгорье Алтая - территория, на которой отмечаются значительные климатические и гидрологические изменения в последние десятилетия.

Цель: оценить в предгорьях Алтая изменение изотопного состава атмосферных осадков, отобранных в исследуемый период в соответствие с рекомендациями GNIP, и сравнить их с данными интерполяции на основе раннее полученных результатов по сети GNIP для сопредельных территорий.

Методика. Отбор проб атмосферных осадков осуществлялся в соответствии с критериями GNIP. Синоптический анализ проводился с учетом данных метеонаблюдений ближайшей метеостанции Росгидромета. Изотопный анализ атмосферных осадков был выполнен методом лазерной абсорбционной ИК-спектрометрии на приборе PICARRO L2130-і. Полученные результаты сравнивали с интерполированными данными GNIP для предгорной зоны Алтая, рассчитанными с помощью ISOtopic GRIdded Rainfall Data Software (ISOGRIDS) и Isoscapes Modeling, Analysis and Prediction (ISOMAP).

Результаты. Анализ изотопного состава атмосферных осадков, отобранных в 2016 г. в предгорьях Алтая в соответствие с рекомендациями GNIP, показал их существенное варьирование. Сравнение изотопного состава атмосферных осадков, одновременно отбиравшихся на изучаемой территории по двум схемам (индивидуальный отбор и ежемесячный), показало высокую степень согласованности, что позволяет при ограниченных условиях применять только их ежемесячный (не событийный) отбор. Сравнение средневзвешенных месячных значений изотопного состава отобранных атмосферных осадков и рассчитанных в IsoMAP и ISOGRIDS показало максимальные отличия в феврале и сентябре. Выявленные отличия связаны с особенностями синоптических условий 2016 г., а именно с устойчивыми положительными температурами в феврале, что нетипично для исследуемой территории, и небольшой повторяемостью осадков в сентябре.
\end{abstract}

\section{Ключевые слова:}

Атмосферные осадки, изотопный состав, данные наблюдений, данные интерполяции, предгорья Алтая.

\section{Введение}

В последние десятилетия в качестве надежных маркеров гидрологических и климатических изменений эффективно используют стабильные изотопы кислорода $\left(\delta^{18} 0\right)$ и водорода $\left(\delta^{2} \mathrm{H}\right)[1,2]$. Активное изучение изотопного состава, в частности в атмосферных осадках, началось в середине прошлого века, что послужило толчком к организации Global Network of Isotopes in Precipitation (GNIP) под патронажем Международного агентства по атомной энергии (МАГАТЭ) и Всемирной метеорологической организации (ВМO) [3]. Peзультаты ежемесячных наблюдений по унифицированной методике на станциях GNIP, а также дополнительные исследования в других регионах позволили установить, что соотношения стабильных изотопов в атмосферных осадках в различной степени могут отражать: характер взаимодействия между источником водяного пара и местом выпадений атмосферных осадков; температуру конденсации водяного пара; абсолютную высоту и географическую широту места их выпадения, а также ряд других параметров $[4,5]$. Соотношения стабильных изотопов кислорода и водорода в атмосферных осадках описывают эмпирической зависимостью, получившей название - глобальная линия метеорных вод (ГЛМВ, $\left.\delta \mathrm{D}=8 \times \delta^{18} \mathrm{O}+10\right)[4,6]$. По отклонению изотопных отношений $\delta^{18} 0 \ldots \delta \mathrm{D}$ от ГЛМВ возможно оценить процессы изотопного фракционирования, которые приводят к тому, что изменения в системе $\delta^{18} 0$ и $\delta \mathrm{D}$ конкретного региона характеризуются локальной линией метеорных 
вод (ЛЛМВ). Кроме того, предложенный В. Дансгором на основе ГЛМВ-зависимости расчетный показатель - дейтериевый эксцесс (d-excess - coкращенно $\left.\mathrm{d}_{\text {exc }}=\delta \mathrm{D}-8 \times \delta^{18} 0\right)$, успешно применяют для оценки источников поступления атмосферных осадков (водяного пара) [7, 8].

В последние годы наблюдается рост числа работ по изучению пространственных и временных изменений соотношений изотопов кислорода и водорода в атмосферных осадках как в глобальном масштабе, так и в конкретных регионах, имеющих «густую» сеть станций GNIP. Работы такого плана в настоящее время активно проводятся в США [9], Новой Зеландии [10], Швейцарии [11, 12], Китае $[13,14]$.

На обширной территории Российской Федерации (бывшего СССР) в разное время одновременно функционировало не более 35 станций GNIP, проводивших отбор проб атмосферных осадков хотя бы в течение года и более, из них в азиатской части страны только на 19 станциях велись редкие наблюдения. Наиболее длительный период наблюдений и отбора проб атмосферных осадков по методике GNIP в азиатской части России осуществлялся в г. Якутске (с 1969 по 2000 гг. отобрано и проанализировано 54 пробы), г. Петропавловск-Камчатский (с 1969 по 1990 гг. - 42 пробы), г. Иркутске (с 1969 по 1990 гг. - 14 проб) и в г. Новосибирске (с 1969 по 1990 гг. лишь 12 проб) (рис. 1) [1]. Определение изотопного состава в сезонных атмосферных осадках и ледниковых кернах в нивально-гляциальных областях России проводили во время работы российско-швейцарской [15] и российско-японско-американской [16] экспедиций на Алтае, а также российской экспедиции на Кавказе [17]. К сожалению, и на равнинной территории России выполнено небольшое количество работ по изучению изотопного состава атмосферных осадков [18-25].
Проведенные исследования изотопного состава атмосферных осадков на территории России в своем большинстве не соответствуют критериям международной сети GNIP, хотя именно данные изотопного состава атмосферных осадков необходимы для «изотопного» гидрологического и климатического моделирования и могут быть использованы при планировании, проектировании, эксплуатации и устойчивом управлении водными ресурсами, а также для расчётов региональных климатических прогнозов [26]. Эти исследования особенно важны для горных и предгорных территорий, характеризующихся значительными колебаниями гидрологических и климатических условий, что становится еще более актуальным в условиях интенсивно изменяющегося климата. Перспективным районом исследования в этом отношении является предгорье Алтая, так как расположено на границе равнин юга Западной Сибири и основных орографических барьеров Алтая. Территорию предгорий отличает от соседних равнин большее количество осадков и более мощный снежный покров, что обуславливает уникальные условия увлажнения. В гидрологическом режиме значительную роль играют талые воды, так как за холодный период выпадает до 40 \% от годового количества осадков, а вклад талого стока составляет 60-80\% от годового стока [27]. Стоит отметить, что год от года климатическая и гидрологическая обстановки в предгорьях Алтая резко меняются, что может приводить к катастрофическим последствиям, как, например, наводнения в 2014 и 2018 гг. на Алтае [28, 29]. Таким образом, целью настоящей работы стала оценка изменений изотопного состава атмосферных осадков, отобранных в предгорьях Алтая в соответствии с рекомендациями GNIP, a также их сравнение с интерполированными данными, полученными ранее по сети GNIP для сопредельных территорий.

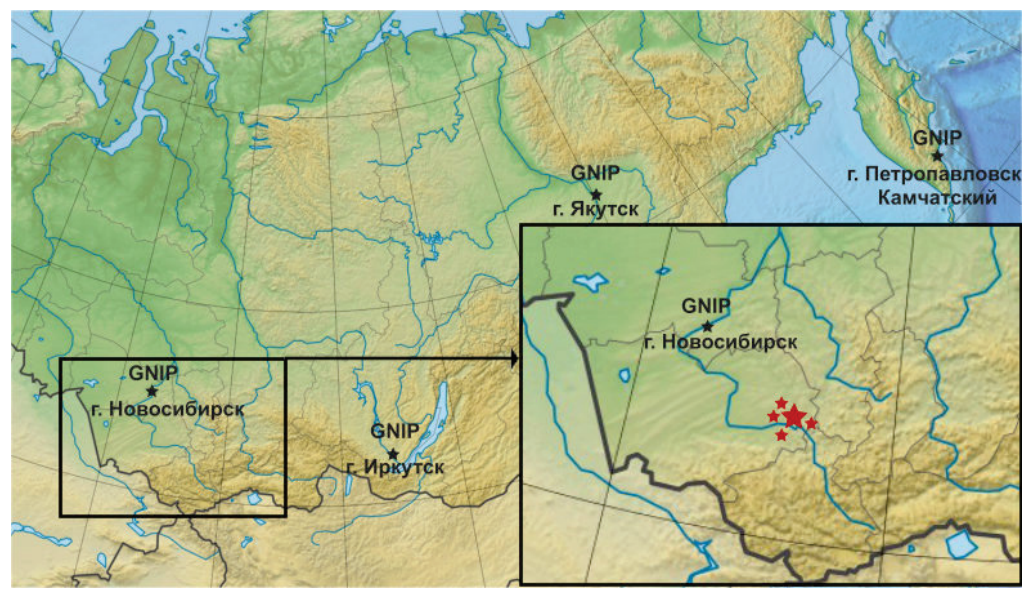

Puc. 1. Станиии GNIP в азиатской части России, имеющие наиболее длительные ряды наблюдений, и врезка с местоположениел точек отбора проб в предгорьях Алтая: опорная точка МС Зональное - большая красная звездочка, и точки, расположенные на удалении не более 100 км от МС Зональное - маленькие красные звездочки

Fig. 1. GNIP stations in the Asian part of Russia with long observational data and an insert with the location of sampling points in Altai foothills: the main point of the WS Zonalnoe is a large red star and points located at a distance of not more than $100 \mathrm{~km}$ from the WS Zonalnoe - small red asterisks 


\section{Материалы и методы}

Отбор проб атмосферных осадков, выпадающих на территории предгорий Алтая, проводился по двум схемам. Первая схема отбора применялась для получения достоверной сопутствующей метеорологической информации и в соответствии с критериями GNIP представляла ежемесячный (непрерывный в течение 30-31 дней) отбор проб атмосферных осадков на точках, расположенных на некотором удалении (не более 100 км) от метеорологической станции (МC - Зональное, Алтайский край). Вторая схема включала отбор проб в опорной точке (52,3‥ш., 85,1 $1^{\circ}$ в.д., высота над ур. моря 270 м) в каждом случае выпадения осадков непосредственно после их прекращения с фиксацией наблюдаемых синоптических условий (рис. 1). В соответствии с рекомендациями GNIP отбор проб по двум схемам на Алтае реализовывался впервые. Непосредственно после отбора проводили измерение объема проб, затем их упаковывали в герметичные пробирки, которые хранили в холодильнике до начала изотопного анализа. В холодный период года, когда выпадали твердые атмосферные осадки (снег), пробы снега таяли в закрытых пластиковых пакетах, а затем помещали в герметичные пробирки, которые также хранили в холодильнике до начала анализа. Всего за период с 01 января по 01 ноября 2016 г. было отобрано 111 индивидуальных проб и 42 месячные пробы атмосферных осадков.

Синоптические условия в период выпадения атмосферных осадков оценивали на основе метеонаблюдений в непосредственной близости от точки отбора осадков. Кроме того, использовали данные Росгидромета и Национального управления океанических и атмосферных исследований (National Oceanic and Atmospheric Administration - NOAA), представленные на сайтах [30, 31].

Изотопный анализ атмосферных осадков был выполнен в Химико-аналитическом центре Института водных и экологических проблем СО РАН методом лазерной абсорбционной ИК-спектрометрии на приборе PICARRO L2130-i, оснащённом системой WS-CRDS (Wavelength-Scanned Cavity Ring Down Spectroscopy). Точность измерения $\delta^{18} 0$ и $\delta \mathrm{D}$ $(1 \sigma, \mathrm{n}=5)$ составляла $\pm 0,1$ и $\pm 0,4 \%$ о соответственно, а в качестве стандартов использовали пробы воды, откалиброванные относительно Международного стандарта V-SMOW-2 (MAГАТЭ).

В настоящей работе использовали программное обеспечение ISOtopic GRIdded Rainfall Data Software (ISOGRIDS), которое было разработано для расчетов и визуализации данных изотопного состава атмосферных осадков по градусной сетке в глобальном масштабе на основе значений GNIP [32]. Разработка ISOGRIDS осуществлялась в рамках проекта «Geostatistical Methods of Spatial Isotope Variability to Map the Sources of Water for Hydrology and Climate Studies», который реализовывался под эгидой МАГАТЭ. Дополнительно привлекали данные, полученные из онлайн-калькулятора, размещенного на портале Isoscapes Modeling, Analysis and Prediction (IsoMAP) [33].

\section{Результаты и обсуждение}

Анализ синоптических условий 2016 г., а именно данных восьмисрочных наблюдений температуры воздуха на МC Зональное, показал (рис. 2), что в феврале наблюдалось два продолжительных периода повышения температуры. Резкий кратковременный рост температур также был зафиксирован в апреле, а максимум - в июне. Стоит отметить, что в октябре 2016 г. преобладали отрицательные температуры воздуха, что нетипично для этого периода. Максимальные атмосферные осадки в предгорной зоне Алтая отмечались в июле месяце (более 25 мм) - два события, а более $10 \mathrm{mм}$ за срок наблюдения выпадали в апреле, мае, июне, июле и октябре (рис. 2).

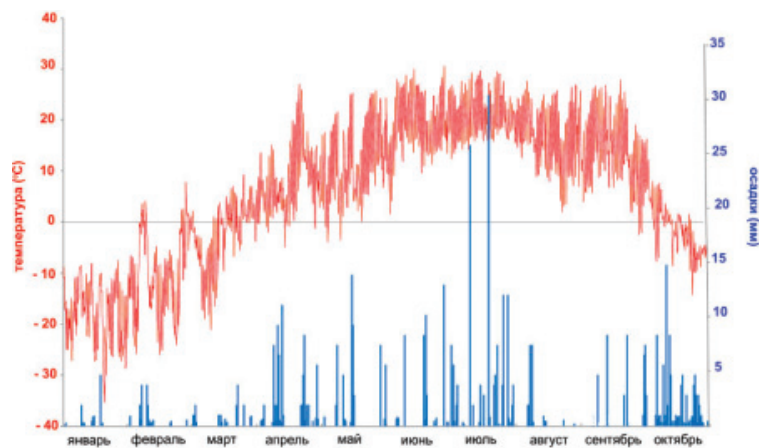

Pис. 2. Температура воздуха и атлосферные осадки (по данныл метеостанции Зональное) в январе-октябре 2016 г.

Fig. 2. Air temperature and precipitation (data from weather station Zonalnoe) in January-October 2016

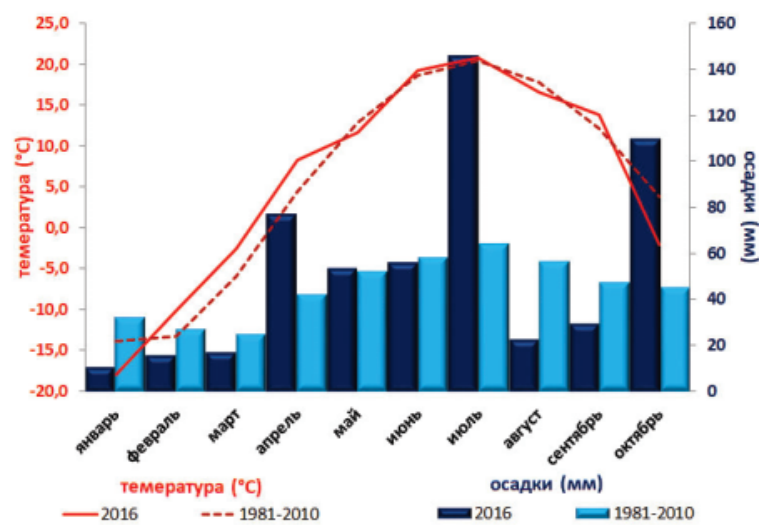

Puс.3. Температура воздуха и атлосферные осадки в предгорной зоне Алтая (летеостаниия Зональное) за период с января по октябрь 2016 г. и средние значения для $1981-201022$

Fig. 3. Air temperature and precipitation in Altai foothills (weather station Zonalnoe) for the period from January to October 2016 and average data for 1981-2010

При сравнении месячных значений температуры и осадков 2016 г. со средними значениями за 1981-2010 гг. в предгорьях Алтая (по данным метеостанции Зональное) наблюдаются резкие различия. Так, средняя температура в феврале, марте и апреле 2016 г. была выше (на $3{ }^{\circ} \mathrm{C}$ ) среднемесячных значений 1981-2010 гг., а в январе и октябре - ниже на 4 и $6{ }^{\circ} \mathrm{C}$ соответственно. При этом осадков в 2016 г. выпадало больше в апреле (на 35 мм), июле 


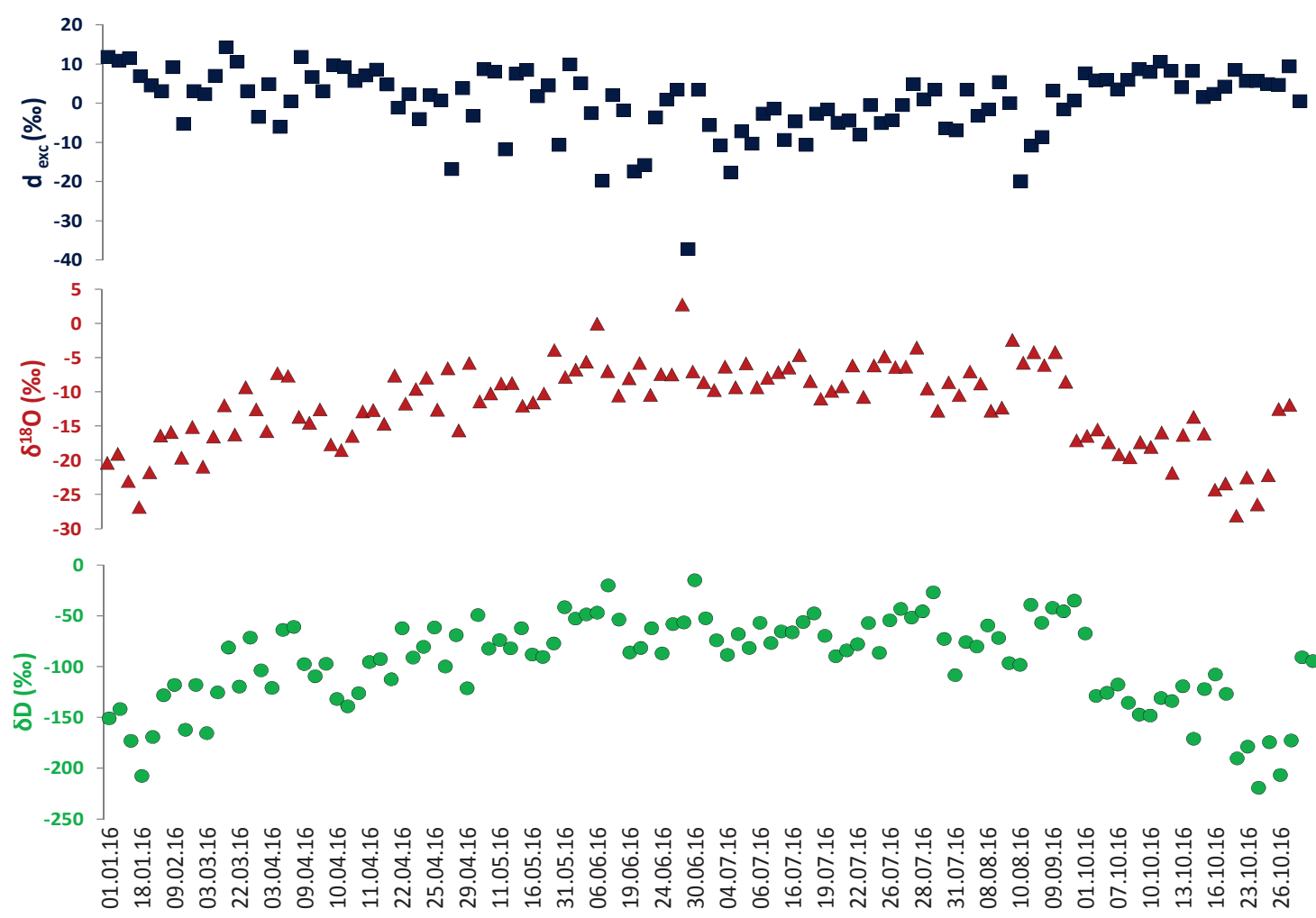

Pис. 4. Изотопный состав атмосферных осадков, выпадавших в январе--октябре 2016 г. в предгорьях Алтая (индивидуальный отбор)

Fig. 4. Isotopic composition of precipitation in January-October 2016 in Altai foothills (daily sampling)

(на 82 мм) и октябре (на 64 мм), чем в среднем в эти же месяцы 1981-2010 гг. Однако в январе, августе и сентябре осадков было существенно меньше - на 21, 33 и 31 мм соответственно (рис. 3).

Анализ погодных условий в предгорьях Алтая показал, что в феврале 2016 г. отмечалось два случая с устойчивым переход температуры воздуха через $0{ }^{\circ} \mathrm{C}$, а максимальные температуры были зафиксированы в июне. Максимальное количество осадков было зарегистрировано в июле 2016 г.
Изотопный анализ 111 индивидуальных проб атмосферных осадков, отобранных в предгорьях Алтая за период с января по октябрь 2016 г., показал существенное варьирование как для $\delta^{18} \mathrm{O}$ $-28,12 \ldots+2,78 \%$, так и для $\delta \mathrm{D}-219,3 \ldots-15,0 \%$, и как следствие - для $\mathrm{d}_{\mathrm{exc}}-37,3 . .+14,3 \%$ (рис. 4). Полученные результаты позволяют предположить значительное влияние криогенного (в холодный сезон) и испарительного (чаще в теплый сезон) фракционирования на формирование изотопного

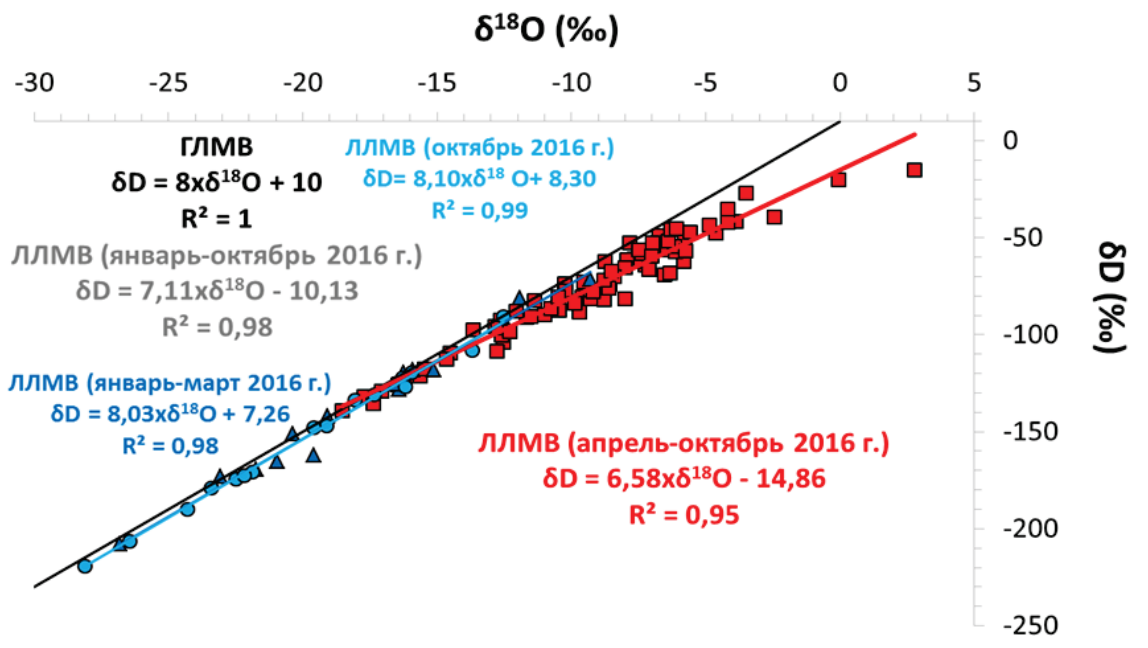

Рис. 5. ЛЛМВ атмосферных осадков, отобранных в предгорьях Алтая (январь-октябрь 2016 г.)

Fig. 5. Local Meteoric Water Line of precipitation collected in Altai foothills (January-October 2016) 
состава атмосферных осадков, а также смену основных регионов-источников поступления атмосферной влаги, выпадавшей в виде осадков.

Рассчитанная ЛЛМВ атмосферных осадков описывается уравнением: $\delta \mathrm{D}=7,11 \times \delta^{18} 0-10,1$ (рис. 5 ). Полученные значения угла наклона меньше значения для ГЛМВ, равного 8, что позволяет говорить о существенном влиянии испарительного фракционирования на изотопный состав атмосферных осадков. Однако при анализе рассчитанных ЛЛМВ по сезонам: холодный (атмосферные осадки выпадали в виде снега с января по март - I период и с 16 по 30 октября - II период) и теплый (осадки - в виде дождя с апреля по 15 октября), наблюдаются существенные различия. Так, для холодных периодов ЛЛМВ описывается уравнениями: $\delta \mathrm{D}=8,03 \times \delta^{18} \mathrm{O}+7,26$ (I период) и $\delta \mathrm{D}=8,10 \times \delta^{18} \mathrm{O}+8,30$ (II период), при этом углы наклона несколько превышают значения для ГЛМВ, что указывает на преимущественное влияние криогенного фракционирования на формирование изотопного состава атмосферных осадков. ЛЛМВ для теплого периода описывается уравнением: $\delta \mathrm{D}=6,58 \times \delta^{18} \mathrm{O}-14,8$, а значение углового коэффициента $<8$ свидетельствует о влиянии испарительного фракционирования и/или смене источников атмосферной влаги, выпадающей в виде осадков.

Таким образом, результаты изотопного анализа проб атмосферных осадков, отобранных в предго-
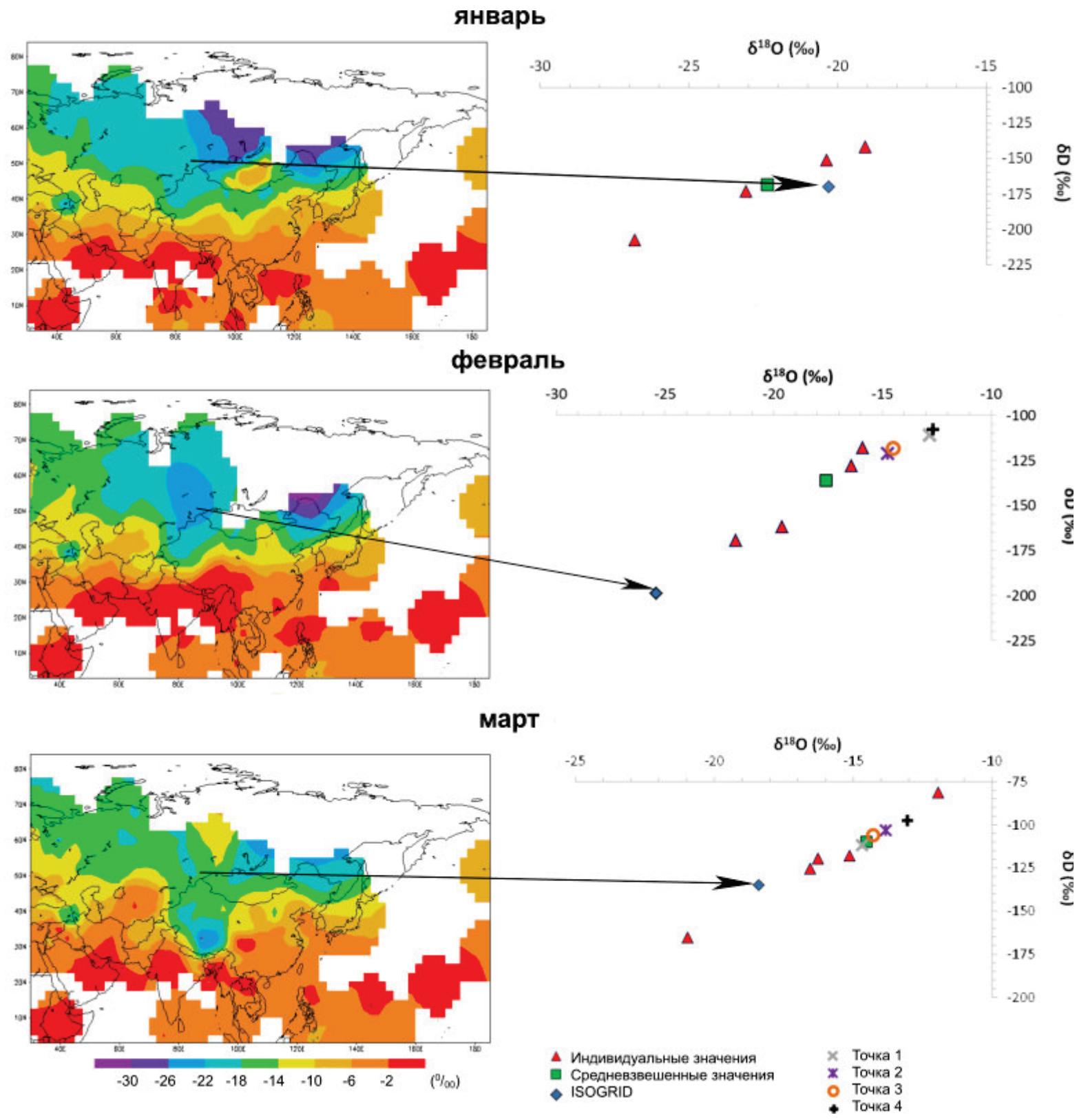

Puc. 6. Картосхемы ISOGRIDS и значения изотопного состава атлосферных осадков, отобранных в предгорьях Алтая (первый холодный период)

Fig. 6. ISOGRIDS and isotopic composition of precipitation collected in Altai foothills (the first cold period) 
рьях Алтая в январе-октябре 2016 г., показали значительное варьирование изотопного состава, а именно: для $\delta^{18} \mathrm{\sim} \sim 31 \%$, для $\delta \mathrm{D} \sim 204 \%$ и для $\mathrm{d}_{\text {ехс }} \sim 52 \%$. В совокупности с данными рассчитанных ЛЛМВ есть все основания с большой степенью вероятности говорить о влиянии криогенного фракционирования на формирование изотопного состава атмосферных осадков в холодные периоды 2016 г. и испарительного фракционирования и/или смену источников поступления атмосферных осадков в теплый период 2016 г.
Рассчитанные для каждого месяца средневзвешенные значения изотопного состава атмосферных осадков и данные, полученные для проб осадков, непрерывно отбиравшихся в течение месяца, были сопоставлены с данными ISOGRIDS. Важно отметить, что наиболее близко расположенная станция GNIP (г. Новосибирск) находится на удалении порядка 200 км по прямой от района исследования. Отбор проб атмосферных осадков на этой станции для последующего изотопного анализа осуществлялся в 1969-1990 гг., при этом было
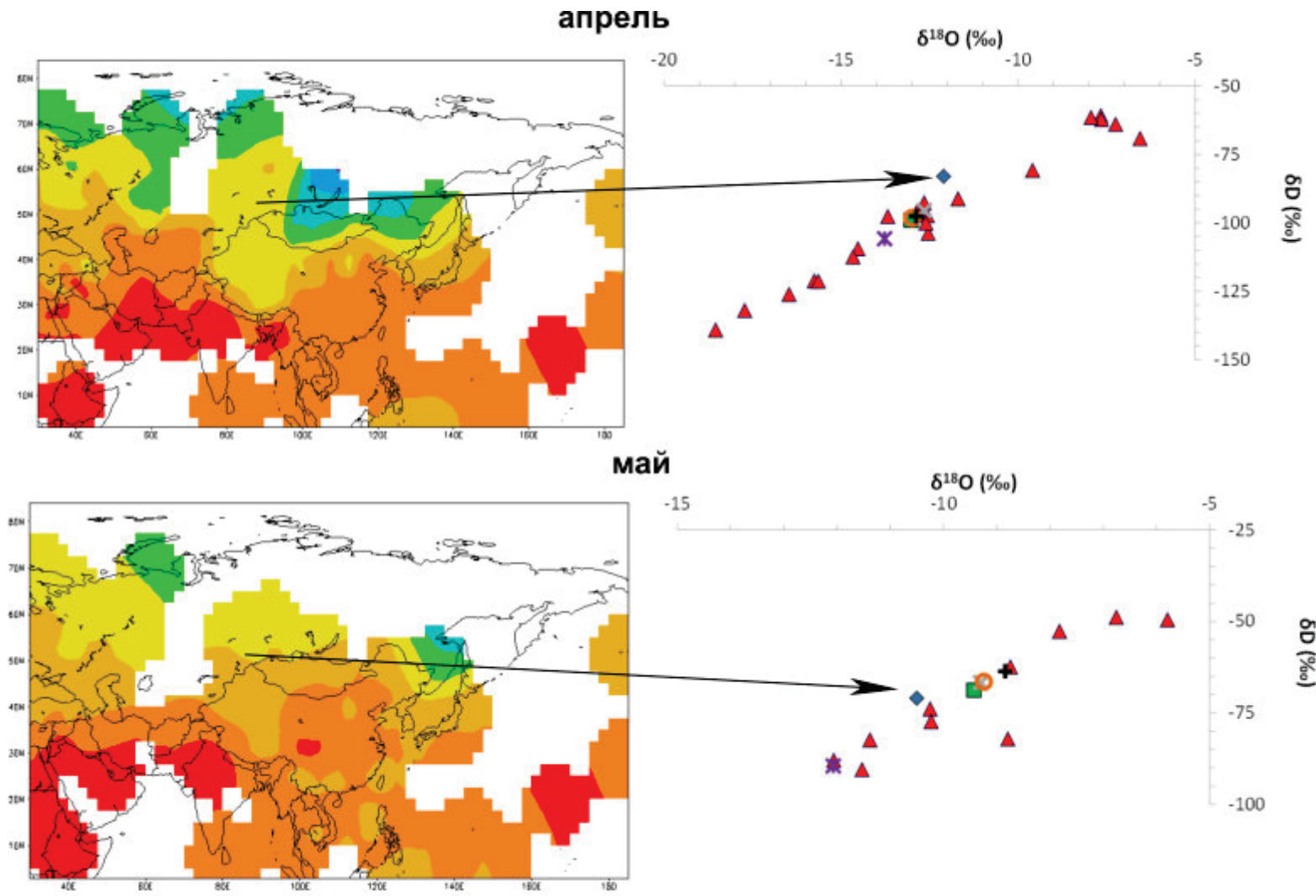

\section{июнь}

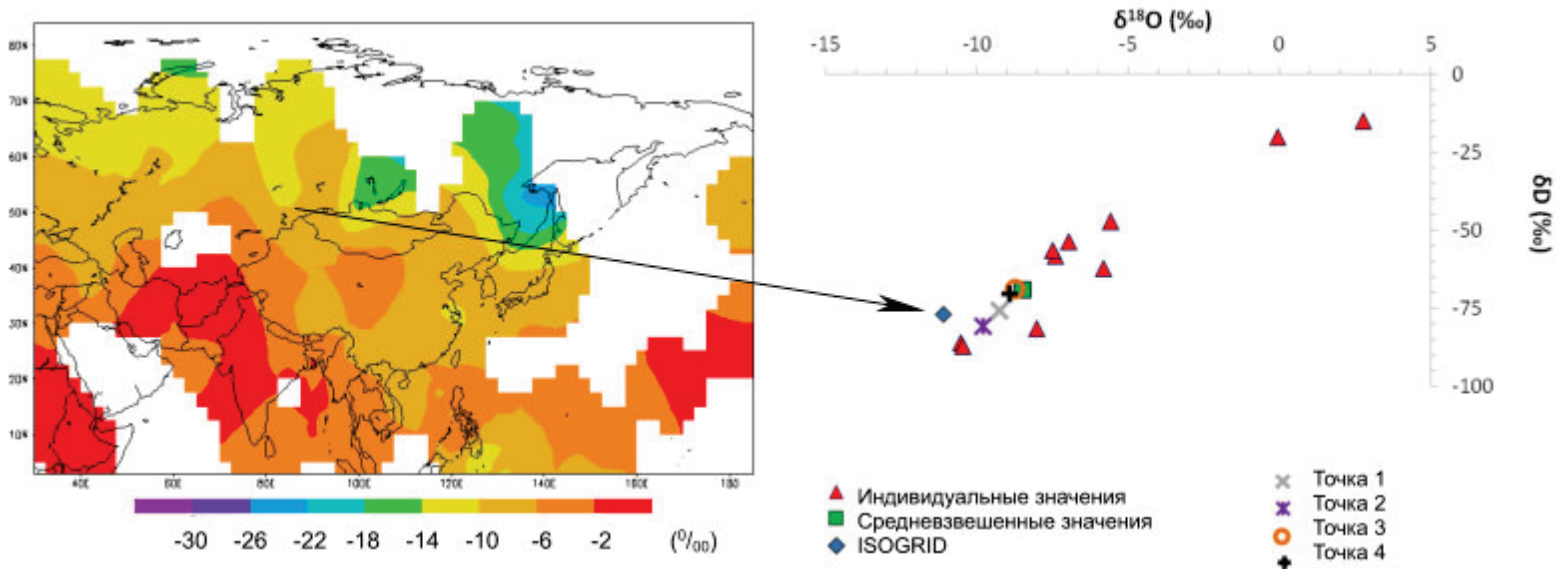

Puc. 7. Картосхемы ISOGRIDS и значения изотопного состава атмосферных осадков, отобранных в предгорьях Алтая

Fig. 7. ISOGRIDS and isotopic composition of precipitation collected in Altai foothills (the warm period) 
октябрь

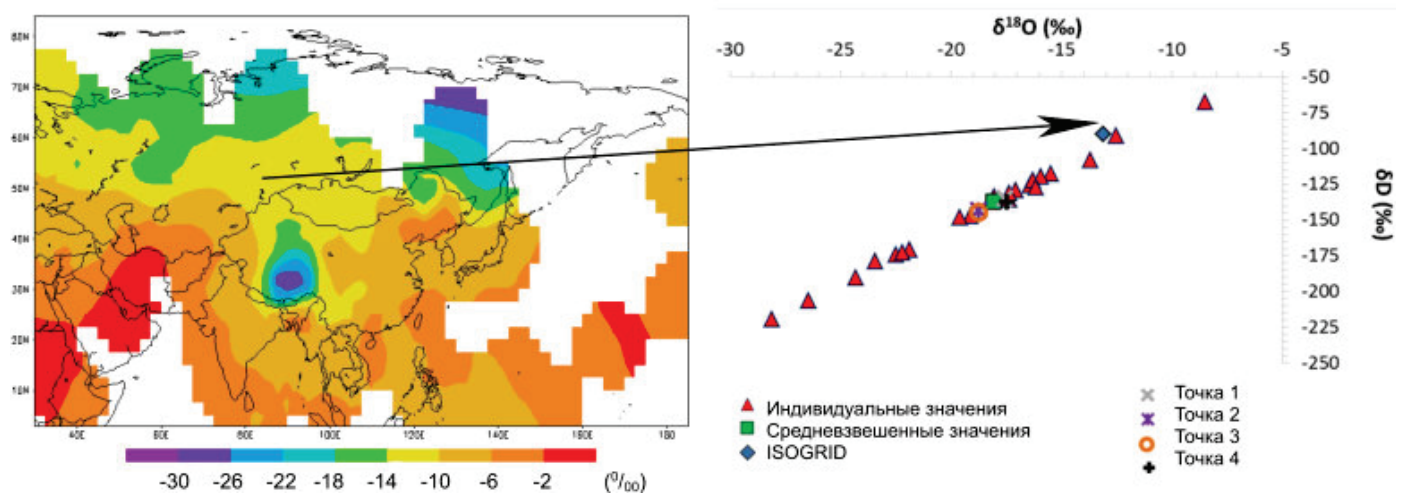

Puc. 8. Картосхема ISOGRIDS и значения изотопного состава атлосферных осадков, отобранных в предгорьях Алтая

Fig. 8. ISOGRIDS and isotopic composition of precipitation collected in Altai foothills (the second cold period)

проанализировано всего 12 проб. Именно эти немногочисленные данные использовались при интерполяции ISOGRIDS.

В первом холодном периоде (январь-март) значения изотопного состава атмосферных осадков в целом были близки, однако в феврале по данным ISOGRIDS изотопный состав атмосферных осадков характеризовался более облегченными значениями (почти на $8 \%$ дляя $\delta^{18} 0$ и $63 \%$ для $\left.\delta \mathrm{D}\right)$ (рис. 6$)$. По нашему мнению, выявленные различия для февраля скорее всего обусловлены влиянием испарительного фракционирования в 2016 г., что подтверждают значения положительных температур окружающей среды в период выпадения атмосферных осадков. Вышеуказанная разница в изотопном составе атмосферных осадков может быть связана также и с тем, что сравнивались разные временные интервалы: январь-март 2016 г. - результаты настоящей работы и соответствующие месяцы, но в 1969-1990 гг. - ISOGRIDS.

Сравнения данных изотопного состава атмосферных осадков, представленных в ISOGRIDS для теплого периода (апрель-сентябрь), с данными для предгорий Алтая показали наиболее близкие результаты для апреля, мая и июня (рис. 7), в то время как максимальные отличия наблюдались в июле и сентябре. Полученные различия в значительной степени связаны со сменой регионов-источников поступления атмосферных осадков, что подтверждается данными синоптического анализа.

При сравнении результатов изотопного состава атмосферных осадков октября 2016 г. и данных ISOGRIDS (рис. 8) определены большие различия в изотопном составе. По данным ISOGRIDS атмосферные осадки в предгорьях Алтая характеризуются более утяжеленным изотопным составом, что, скорее всего, объясняется нетипичными для исследуемого района синоптическими условиями октября 2016 г. выпадение большого количества атмосферных осадков, в первую очередь, в виде снега, что и определило их более облегченный изотопный состав.

Сравнение данных ISOGRIDS и изотопного состава атмосферных осадков, отобранных в предгорьях Алтая в январе-октябре 2016 г., показало хо- рошую согласованность. Однако отличия наблюдались в феврале, июле, сентябре и октябре, что в значительной степени обусловлено нетипичными синоптическими условиями этих месяцев в 2016 г., а именно - устойчивыми положительными температурами в феврале, аномально высоким количеством осадков в июле и октябре и малым количеством случаев выпадения осадков (более $1 \mathrm{mм}$ ) в сентябре.

Онлайн калькулятор, размещенный на портале IsoMAP, дополнительно позволил осуществить анализ ретроспективных данных состава стабильных изотопов в атмосферных осадках, полученных с помощью сети GNIP для исследуемой территории, однако в отличие от ISOGRIDS при интерполяции использовался метод множественной регрессии.

Таблища. Изотопный состав атмосферных осадков в предгорьях Алтая

Table. Isotopic composition of precipitation in Altai foothills

\begin{tabular}{|c|c|c|c|c|c|c|}
\hline & \multicolumn{2}{|c|}{$\begin{array}{c}\text { Средневзвешенные } \\
\text { значения } 2016 \text { г. } \\
\text { Weighted average, } \\
2016\end{array}$} & \multicolumn{2}{|c|}{ ISOGRIDS } & \multicolumn{2}{|c|}{ IsoMAP } \\
\hline & $\delta^{18} 0$ & $\delta \mathrm{D}$ & $\delta^{18} 0$ & $\delta \mathrm{D}$ & $\delta^{18} 0$ & $\delta \mathrm{D}$ \\
\hline & \multicolumn{6}{|c|}{$\% 0$} \\
\hline Январь/January & $-22,4$ & $-168,7$ & $-20,3$ & $-170,0$ & $-20,6$ & $-164,0$ \\
\hline Февраль/February & $-17,6$ & $-136,2$ & $-25,4$ & $-199,0$ & $-24,1$ & $-189,0$ \\
\hline Mарт/March & $-14,5$ & $-110,0$ & $-18,4$ & $-135,0$ & $-18,1$ & $-136,0$ \\
\hline Апрель/April & $-13,0$ & $-99,1$ & $-12,1$ & $-83,0$ & $-13,5$ & $-99,0$ \\
\hline Май/Мау & $-9,4$ & $-68,8$ & $-10,5$ & $-71,0$ & $-11,8$ & $-85,0$ \\
\hline Июнь/June & $-8,5$ & $-69,2$ & $-11,1$ & $-77,0$ & $-10,0$ & $-73,0$ \\
\hline Июль/July & $-7,8$ & $-64,8$ & $-13,9$ & $-99,0$ & $-11,8$ & $-81,0$ \\
\hline Август/August & $-10,4$ & $-81,9$ & $-12,0$ & $-83,0$ & $-10,7$ & $-76,0$ \\
\hline Сентябрь/September & $-5,6$ & $-43,7$ & $-13,9$ & $-89,0$ & $-14,4$ & $-100,0$ \\
\hline Октябрь/October & $-18,1$ & $-137,1$ & $-13,1$ & $-90,0$ & $-15,2$ & $-111,0$ \\
\hline
\end{tabular}

Результаты сравнения средневзвешенных значений изотопного состава атмосферных осадков, отобранных в предгорьях Алтая (январь-октябрь 2016 г.), и данных IsoMAP (таблица) показали, что, как и по данным ISOGRIDS, максимальные отличия отмечаются в сентябре и феврале. Выявленные различия менее значимы для февраля, но более значимы для сентября и связаны с особенностями синоптических условий 2016 г. Следует отметить, 
что IsoMAP и ISOGRIDS в качестве входных параметров используют одни и те же данные, а именно данные GNIP, но при этом применяют различные алгоритмы расчетов, что и обусловило схожесть различия с данными наблюдений в 2016 г. по месяцам - максимальные в феврале и сентябре.

\section{Заключение}

Проведенные исследования изотопного состава атмосферных осадков, отобранных в 2016 г. в предгорьях Алтая в соответствие с рекомендациями GNIP, показали существенное варьирование индивидуальных значений для $\delta^{18} \mathrm{O}-28,12 \ldots+2,78 \%$ и для $\delta \mathrm{D}-219,3 \ldots-15,0 \%$, и как следствие - для $\mathrm{d}_{\text {eхс }}-37,3 \ldots+14,3 \%$. Данные изотопного состава осадков в совокупности с рассчитанными значениями углов наклонов ЛЛМВ позволяют говорить о преимущественном криогенном фракционировании твердых атмосферных осадков, выпадавших в холодные периоды 2016 г., и испарительном фракционировании и/или смене источников поступления осадков в теплый период анализируемого года. Результаты сравнения данных изотопного состава атмосферных осадков, которые в предгорной зоне Ал-

\section{СПИСОК ЛИТЕРАТУРЫ}

1. Joussaume S., Sadourny R., Jouzel J. A general circulation model of water isotope cycles in the atmosphere // Nature. - 1984. V. 311. - P. 24-29.

2. Delavau C. J., Stadnyk T., Holmes T. Examining the impacts of precipitation isotope input $\left(\delta^{18} 0_{\mathrm{ppt}}\right)$ on distributed, tracer-aided hydrological modelling // Hydrology and Earth System Sciences. -2017 . - V. 21. - P. 2595-2614.

3. Global Network of Isotopes in Precipitation (GNIP). URL: http://www-naweb.iaea.org/napc/ih/IHS_resources_gnip.html (дата обращения 01.03.2018).

4. Craig H. Isotopic variations in meteoric waters // Science. 1961. - V. 133. - P. 1702-1703.

5. Dansgaard W. Stable isotopes in precipitation // Tellus. 1964. - V. 16. - P. 436-468.

6. Rozanski K., Aragufis-Aragufis L., Gonfiantini R. Isotopic patterns in modem global precipitation. Climate Change in Continental Isotopic Records // Geophysical Monograph Series. - 1993. V. 78. - P. 1-36.

7. Merlivat L., Jouzel J. Global climatic interpretation of the deuterium-oxygen 18 relationship in precipitation // Journal of Geophysical Research. - 1979. - V. 84. - P. 5029-5033.

8. Fricke H., 0 'Neil J. The correlation between ${ }^{18} 0 /{ }^{16} \mathrm{O}$ ratios of meteoric water and surface temperature: its use in investigating terrestrial climate change over geologic time // Earth and Planetary Science Letters. - 1999. - V. 170. - P. 181-196.

9. Arctic Vortex changes alter the sources and isotopic values of precipitation in northeastern US / T. Puntsag, M.J. Mitchell, J.L. Campbell, E.S. Klein, G.E. Likens, J.M. Welker // Scientific Reports. - 2016. - V. 6. DOI: 10.1038/srep22647.

10. Precipitation isoscapes for New Zealand: enhanced temporal detail using precipitation-weighted daily climatology / W.T. Baisden, E.D. Keller, R. van Hale, R.D. Frew, L.I. Wassenaar // Isotopes in Environmental and Health Studies. - 2016. - V. 52. P. $343-352$.

11. Kern Z., Kohán B., Leuenberger M. Precipitation isoscape of high reliefs: interpolation scheme designed and tested for monthly resolved precipitation oxygen isotope records of an Alpine domain // тая впервые отбирались одновременно по двум схемам (индивидуальный отбор и ежемесячный), показали их согласованность, что позволяет при ограниченных условиях применять только ежемесячный отбор проб в соответствии с рекомендациями GNIP. Сопоставление средневзвешенных месячных значений изотопного состава атмосферных осадков с данными значений IsoMAP и ISOGRIDS выявило максимальные отличия в феврале и сентябре. Эти различия связаны с особенностями синоптических (погодных) условий 2016 г., а именно: устойчивыми положительными температурами в феврале, что нетипично для исследуемой территории, и малой повторяемостью осадков в сентябре. Полученные результаты изотопного состава атмосферных осадков могут быть использованы как входные параметры при «изотопном» моделировании региональных гидрологических и климатических изменений в предгорьях Алтая, а также в верификации результатов при глобальном моделировании.

Авторы благодарят старшего научного сотрудника Лаборатории физики атмосферно-гидросферных процессов ИВЭП СО РАН Галину Станиславовну Зинченко за помощь при анализе синоптической ситуации.

Atmospheric Chemistry and Physics. - 2014. - V. 14. P. 1897-1907.

12. Dietermann N., Weiler M. Spatial distribution of stable water isotopes in alpine snow cover // Hydrology and Earth System Sciences. -2013 . - V. 17. - P. 2657-2668.

13. Zhang M., Wang S. A review of precipitation isotope studies in China: Basic pattern and hydrological process // Journal of Geographical Sciences. - 2016. - V. - 26. - P. 921-938.

14. Wang T., Chen J., Li L. Entropy analysis of stable isotopes in precipitation: tracing the monsoon systems in China / Scientific Reports. - 2016. - V. 6. DOI: 10.1038/srep30389.

15. Temporal variations of accumulation and temperature during the past two centuries from Belukha ice core, Siberian Altai / K. Henderson, A. Laube, H.W. Gaggeler, S. Olivier, T. Papina, M. Schwikowski // Journal of Geophysical Research. - 2006. V. 111. - D03104. D0I: 10.1029/2005JD005819.

16. Stable isotopes time series and precipitation origin from the Altai glaciers, Siberia, recovered from firn-cores and snow samples / V.B. Aizen, E.M. Aizen, K. Fujita, S.A. Nikitin, K. Kreutz // Journal of Glaciology. - 2005. - V. 51. - P. 637-654.

17. Large-scale drivers of Caucasus climate variability in meteorological records and Mt El'brus ice cores / A. Kozachek, V. Mikhalenko, V. Masson-Delmotte, A. Ekaykin, P. Ginot, S. Kutuzov, M. Legrand, V. Lipenkov, S. Preunkert // Climate of the Past. 2017. - V. 13. - P. 473-489.

18. Пространственно-временные вариации изотопного состава кислорода атмосферных осадков и речных вод на территории северной части Евразии и их связь с изменением температуры / В.С. Брезгунов, А.Д. Евсиков, В.И. Ферронский, Л.В. Сальнова // Водные ресурсы. - 1998. - Т. 25. - № 1. - С. 99-104.

19. Relationship between the variation of isotopic ratios and the source of summer precipitation in eastern Siberia / N. Kurita, A. Numaguti, A. Sugimoto, K. Ichiyanagi, N. Yoshi-da // Journal of Geophysical Research. - 2003. - V. 108. - D11339. DOI: 10.1029/2001JD001359.

20. Васильчук Ю.К. Новые данные о тенденции и причинах изменения величины дейтериевого эксцесса в едином снегопаде // ДАН. - 2014. - Т. 459. - № 1. - C. 109-111. 
21. Содержание ${ }^{18} 0$ в атмосферных осадках Москвы в 2014 г. / Ю.Н. Чижова, И.Д. Еремина, Н.А. Буданцева, Г.В. Суркова, Ю.К. Васильчук // Метеорология и гидрология. - 2017. № 1. - C. 78-90.

22. Васильчук Ю.К., Чижова Ю.Н. Высотный градиент распределения $\delta^{18} 0$ и $\delta \mathrm{D}$ в атмоссерных осадках и в снежном покрове высокогорных районов // Криосфера Земли. - 2010. - Т. 14. № 1. - C. 13-21.

23. Denisova N.Y., Gribanov K.G., Werner M. Comparison of the isotopic composition of precipitation and air for three Arctic stations with the results of the ECHAM5-wiso modeling// $23^{\text {rd }}$ International Symposium on Atmospheric and Ocean 0ptics: Atmospheric Physics. - 2017. - V. 10466. DOI: 10.1117/12.2288311.

24. Изотопный состав зимних атмосферных осадков и снежного покрова в предгорьях Алтая / Н.С. Малыгина, А.Н. Эйрих, Н.Ю. Курепина, Т.С. Папина // Лёд и Снег. - 2017. - Т. 57. № 1. - C. 57-68.

25. Изотопный состав и источники атмосферных осадков в Центральной Якутии / Т.С. Папина, Н.С. Малыгина, А.Н. Эйрих, А.А. Галанин, М.Н. Железняк // Криосфера Земли. - 2017. T. XXI. - № 2. - C. 60-69.

26. Delavau C.J., Stadnyk T., Holmes T. Examining the impacts of precipitation isotope input $\left(\delta^{18} 0_{\mathrm{ppt}}\right)$ on distributed, tracer-aided hydrological modelling // Hydrology and Earth System Sciences. -2017 . - V. 21. - P. 2595-2614.
27. Галахов В.П., Губарев М.С., Назаров А.Н. Водный баланс бессточных озерно-речных систем Обь-Иртышского междуречья (в пределах Алтайского края). - Барнаул: Изд-во Алтайский государственный университет, 2010. - 112 с.

28. Экстремальный дождевой паводок 2014 г. в бассейне Верхней Оби: причины, прогноз и натурные наблюдения / А.Т. Зиновьев, К.Б. Кошелев, А.В. Дьяченко, А.А. Коломейцев // Водное хозяйство России. Проблемы, технологии, управление. - 2015. - № 6. - С. 93-104.

29. Люцигер А.Ю. Аномальный паводок 2014 года на Алтае // Водные и экологические проблемы Сибири и Центральной Азии: тр. Всерос. науч. конф. с междунар. участием. - Барнаул: ИВЭП СО РАН, 2014. - С. 118-129.

30. Расписание погоды. URL: http://rp5.ru/docs/about/ru (дата обращения 18.09.2017).

31. NOAA Earth System Research Laboratory. URL: http://www.esrl.noaa.gov/ (дата обращения 22.10.2017).

32. Department of Nuclear Sciences and Applications. URL: http://www-naweb.iaea.org (дата обращения 13.12.2017).

33. IsoMAP. URL: http://isomap.rcac.purdue.edu:8080/gridsphere/gridsphere (дата обращения 02.12.2017).

Поступила 30.08.2018 г.

\section{Информация об авторах}

Малыгина Н.C., кандидат географических наук, старший научный сотрудник Химико-аналитического центра Института водных и экологических проблем СО РАН; доцент географического факультета Алтайского государственного университета.

Эйрux A.H., кандидат технических наук, научный сотрудник Химико-аналитического центра Института водных и экологических проблем СО РАН.

Kypenuна H.Ю., кандидат географических наук, старший научный сотрудник Лаборатории водных ресурсов и водопользования Института водных и экологических проблем СО РАН.

Папина T.C., доктор химических наук, начальник Химико-аналитического центра Института водных и экологических проблем СО РАН. 


\title{
ISOTOPIC COMPOSITION OF PRECIPITATION IN ALTAI FOOTHILLS: OBSERVATION AND INTERPOLATION DATA
}

\author{
Natalia S. Malygina", \\ natmgn@gmail.com \\ Alla N. Eirikh', \\ allnik608@gmail.com \\ Nadezhda Yu. Kurepina', \\ nyukurepina@mail.ru \\ Tatiana S. Papina', \\ tanya.papina@mail.ru \\ 1 Institute for Water and Environmental Problems SB RAS, \\ 1, Molodezhnaya street, Barnaul, 656038, Russia. \\ ${ }^{2}$ Altai State University, \\ 61, Lenin avenue, Barnaul, 656049, Russia.
}

Relevance. In recent years, the ratios of oxygen and hydrogen stable isotopes in precipitation obtained from the Global Network of Isotopes in Precipitation (GNIP) have been widely used as reliable markers of current and predicted climatic and hydrological changes. However, for the vast territory of Russia such data sets are essentially limited both in space and in time. One of the most promising stu$d y$ areas is the Altai foothills subjected to significant hydrological and climatic changes in the last decades.

The aim of the research is to assess the changes in isotopic composition of precipitation sampled in the Altai foothills during the study period in accordance with the GNIP recommendations, and to compare the assessment results with the interpolated GNIP data on the adjacent territories. Methods. Precipitation was sampled in accordance with the GNIP criteria. The synoptic analysis was supported by the meteorological data from the nearest «Roshydromet» weather station. The isotopic analysis of precipitation was performed by means of laser absorption IR spectrometry on PICARRO L2130-i device. The obtained results were compared with the interpolated GNIP data for the Altai foothills calculated with the use of ISOtopic GRIdded Rainfall Data Software (ISOGRIDS) and Isoscapes Modeling, Analysis and Prediction (IsoMAP). Results. The analysis of isotopic composition of precipitation sampled in accordance with GNIP requirements in the Altai foothills in 2016 indicated its significant variation. The comparison of isotopic composition of precipitation simultaneously sampled in the study area using two schemes (daily and monthly sampling) shows good correlation; under limited conditions, just monthly sampling is probable. The comparison of weighted average monthly values of isotopic composition of the observed atmospheric precipitation and of that calculated by IsoMAP suggests maximum differences in February and September that is true for comparison with ISOGRIDS data as well. The revealed differences are related to the synoptic peculiarities of 2016, namely, atypically stable positive temperature in February and insignificant precipitation recurrence (more than $1 \mathrm{~mm}$ ) in September.

Key words:

Precipitation, isotopic composition, observation data, interpolation data, Altai foothills.

The authors appreciate Galina S. Zinchenko, a researcher of the Laboratory of Atmosphere-Hydrosphere Physics IWEP SB RAS, for synoptic situation analysis.

\section{REFERENCES}

1. Joussaume S., Sadourny R., Jouzel J. A general circulation model of water isotope cycles in the atmosphere. Nature, 1984, vol. 311 , pp. 24-29.

2. Delavau C. J., Stadnyk T., Holmes T. Examining the impacts of precipitation isotope input $\left(\delta^{18} \mathrm{O}_{\mathrm{ppt}}\right)$ on distributed, tracer-aided hydrological modelling. Hydrology and Earth System Sciences, 2017, vol. 21, pp. 2595-2614.

3. Global Network of Isotopes in Precipitation (GNIP). Available at: http://www-naweb.iaea.org/napc/ih/IHS_resources_gnip.html (accessed 1 March 2018).

4. Craig H. Isotopic variations in meteoric waters. Science, 1961, vol. 133, pp. 1702-1703.

5. Dansgaard W. Stable isotopes in precipitation. Tellus, 1964, vol. 16. pp. 436-468.

6. Rozanski K., Aragufis-Aragufis L., Gonfiantini R. Isotopic patterns in modem global precipitation. Climate Change in Continental Isotopic Records. Geophysical Monograph Series, 1993, vol. 78, pp. 1-36.
7. Merlivat L., Jouzel J. Global climatic interpretation of the deuterium-oxygen 18 relationship in precipitation. Journal of Geophysical Research, 1979, vol. 84, pp. 5029-5033.

8. Fricke H., 0 'Neil J. The correlation between ${ }^{18} \mathrm{O} /{ }^{16} \mathrm{O}$ ratios of meteoric water and surface temperature: its use in investigating terrestrial climate change over geologic time. Earth and Planetary Science Letters, 1999, vol. 170, pp. 181-196.

9. Puntsag T., Mitchell M.J., Campbell J.L., Klein E.S., Likens G.E., Welker J.M. Arctic Vortex changes alter the sources and isotopic values of precipitation in northeastern US. Scientific Reports, 2016, vol. 6. DOI: 10.1038/srep22647.

10. Baisden W.T., Keller E.D., Van Hale R., Frew R.D., Wassenaar L.I. Precipitation isoscapes for New Zealand: enhanced temporal detail using precipitation-weighted daily climatology. Isotopes in Environmental and Health Studies, 2016, vol. 52, pp. 343-352.

11. Kern Z., Kohán B., Leuenberger M. Precipitation isoscape of high reliefs: interpolation scheme designed and tested for monthly resolved precipitation oxygen isotope records of an Alpine domain. 
Atmospheric Chemistry and Physics, 2014, vol. 14, pp. 1897-1907.

12. Dietermann N., Weiler M. Spatial distribution of stable water isotopes in alpine snow cover. Hydrology and Earth System Sciences, 2013, vol. 17, pp. 2657-2668.

13. Zhang M., Wang S. A review of precipitation isotope studies in China: Basic pattern and hydrological process. Journal of Geographical Sciences, 2016, vol. 26, pp. 921-938.

14. Wang T., Chen J., Li L. Entropy analysis of stable isotopes in precipitation: tracing the monsoon systems in China. Scientific Reports, 2016, vol. 6. DOI: $10.1038 /$ srep30389.

15. Henderson K., Laube A., Gaggeler H.W., Olivier S., Papina T., Schwikowski M. Temporal variations of accumulation and temperature during the past two centuries from Belukha ice core, Siberian Altai. Journal of Geophysical Research, 2006, vol. 111, D03104. D0I: 10.1029/2005JD005819.

16. Aizen V.B., Aizen E.M., Fujita K., Nikitin S.A., Kreutz K. Stable isotopes time series and precipitation origin from the Altai glaciers, Siberia, recovered from firn-cores and snow samples. Journal of Glaciology, 2005, vol. 51, pp. 637-654.

17. Kozachek A., Mikhalenko V., Masson-Delmotte V., Ekaykin A., Ginot P., Kutuzov S., Legrand M., Lipenkov V., Preunkert S. Large-scale drivers of Caucasus climate variability in meteorological records and $\mathrm{Mt} \mathrm{El'brus} \mathrm{ice} \mathrm{cores.} \mathrm{Climate} \mathrm{of} \mathrm{the} \mathrm{Past,} \mathrm{2017,}$ vol. 13 , pp. 473-489.

18. Brezgunov V.S., Evsikov A.D., Ferronskiy V.I., Salnova L.V. Spatio-temporal variations of the isotope composition oxygen of atmospheric precipitation and river water in the territory of the northern part of Eurasia and their relationship with temperature change. Water resources, 1998, vol. 25, pp. 99-104. In Rus.

19. Kurita N., Numaguti A., Sugimoto A., Ichiyanagi K., Yoshi-da N. Relationship between the variation of isotopic ratios and the source of summer precipitation in eastern Siberia. Journal of Geophysical Research, 2003, vol. 108, D11339. D0I: 10.1029/2001JD001359.

20. Vasilchuk Y.K. New date on the tendency and causes of deuterium excess variations during one snowfall. Doklady Earth Sciences, 2014, vol. 459, pp. 109-111. In Rus.

21. Chizhova Yu.N., Eremina I.D., Budantseva N.A., Surkova G.V., Vasilchuk Yu.K. Concentration of ${ }^{18} 0$ in precipitation over Moscow in 2014. Russian Meteorology and Hydrology, 2017, vol. 41, pp. 78-90. In Rus.

22. Vasilchuk Yu.K., Chizhova Ju.N. Altitudinal gradient of $\delta^{18} 0$ and $\delta \mathrm{D}$ in precipitation and snow cover in high mountains. Earths Cryosphere, 2010, vol. 14, pp. 13-21. In Rus.
23. Denisova N.Y., Gribanov K.G., Werner M. Comparison of the isotopic composition of precipitation and air for three Arctic stations with the results of the ECHAM5-wiso modeling. 23rd International Symposium on Atmospheric and Ocean Optics: Atmospheric Physics, 2017, vol. 10466. D0I: 10.1117/12.2288311.

24. Malygina N.S., Eirikh A.N., Kurepina N.Yu., Papina T.S. Isotope composition of winter precipitation and snow cover in the foothills of the Altai. Ice and snow, 2017, vol. 57, pp. 57-68. In Rus.

25. Papina T.S., Malygina N.S., Eirikh A.N., Galanin A.A., Zheleznyak M.N. Isotopic composition and sources of atmospheric precipitation in Central Yakutia. Earths Cryosphere, 2017, vol. XXI, pp. 60-69. In Rus.

26. Delavau C.J., Stadnyk T., Holmes T. Examining the impacts of precipitation isotope input $\left(\delta^{18} \mathrm{O}_{\mathrm{ppt}}\right)$ on distributed, tracer-aided hydrological modelling. Hydrology and Earth System Sciences, 2017, vol. 21, pp. 2595-2614.

27. Galakhov V.P., Gubarev M.S., Nazarov A.N. Vodny balans besstochnykh ozerno-rechnykh sistem Ob-Irtyshskogo mezhdurechya ( $v$ predelakh Altayskogo kraya) [Water balance of the drainless lake-river systems of the Ob-Irtysh interfluve (within the Altai Territory)]. Barnaul, ASU Publ., 2010. 112 p.

28. Zinoviev A.T., Koshelev K.B., Dyachenko A.V., Kolomeitsev A.A. Extreme Rainfall and Flood Event of 2014 in the Upper ob River Basin: Causes, Prediction and Field Observations. Water management in Russia. Problems, technologies, management, 2015, vol. 6, pp. 93-104. In Rus.

29. Lyuciger A.Yu. Anomalny pavodok 2014 goda na Altae [The abnormal flood of 2014 in the Altai]. Vodnye i ekologicheskie problemy Sibiri i Tsentralnoy Azii. Trudy Vserossiyskoy nauchnoy konferentsii s mezhdunarodnym uchastiem [Water and ecological problems in Siberia and Central Asia. Proc. of All-Russian scientific conference with International participation]. Barnaul, IWEP SB RAS, 2014. pp. 118-129.

30. Raspisanie pogody [Weather schedule]. Available at: http://rp5.ru/docs/about/ru (accessed 18 September 2017).

31. NOAA Earth System Research Laboratory. Available at: http://www.esrl.noaa.gov/ (accessed 22 October 2017).

32. Department of Nuclear Sciences and Applications. Available at: http://www-naweb.iaea.org (accessed 13 December 2017).

33. IsoMAP. Available at: http://isomap.rcac.purdue.edu:8080/ gridsphere/gridsphere (accessed 02 December 2017).

Received: 30 August 2018.

\section{Information about the authors}

Natalia S. Malygina, Cand. Sc., senior researcher, Institute for Water and Environmental Problems SB RAS; associate professor, Altai State University.

Alla N. Eirikh, Cand. Sc., researcher, Institute for Water and Environmental Problems SB RAS.

Nadezhda Yu. Kurepina, Cand. Sc., senior researcher, Institute for Water and Environmental Problems SB RAS.

Tatiana S. Papina, Dr. Sc., principal researcher, Institute for Water and Environmental Problems SB RAS. 